\title{
COMPLEMENTARITY BETWEEN IN SITU STUDIES AND PHOTOGRAMMETRY: METHODOLOGICAL FEEDBACK FROM A ROMAN SHIPWRECK IN CAESAREA, ISRAEL
}

\author{
B. Derenne ${ }^{1}$, E. Nantet ${ }^{2}$, G. Verly ${ }^{1}$, M. Boone ${ }^{4}$ \\ ${ }^{1}$ EACOM-Museum of Art and History - bderenne@ulb.ac.be, g.verly@mrah.be \\ ${ }^{2}$ University of Haifa, The Leon Recanati Institute for Maritime Studies - emmanuelnantet@ gmail.com \\ ${ }^{4}$ Ghent University Centre for X-ray Tomography - Matthieu.Boone@UGent.be
}

\author{
Commission II, WG II/9
}

KEY WORDS: Underwater Archaeology, Roman Shipwreck, Measurements, Photogrammetry, RealityCapture.

\begin{abstract}
:
As a quick and effective way to archive the different stages of an excavation - notably to prepare the post-excavation phase and to document the production methods - photogrammetry has become an indispensable tool. Indeed, it offers a valid scientific model, usable by any member of the team and at any moment, without the need to return to the excavation site. Photogrammetry can also complement other archaeological tools such as manual surveys. The interaction between the complementary approach of the interpretative drawing measurements (IDM) and the photogrammetric model measurements (PMM) enables us to apprehend the error rate of the interpretative measurements in situ. It appears thus that the measurements taken flat have an error rate inferior to $2 \%$ whereas the distances that are either too long or taken on a three-dimensional support have an error rate that can exceed $10 \%$. The input of photogrammetry is therefore an added value whether it be during the excavation phase or during the post-excavation studies.
\end{abstract}

\section{INTRODUCTION}

The Caesarea shipwreck is located off the northern harbour of the city built by Herod (fig. 1 and 2) in the late $1^{\text {st }}$ century BCE (Oleson 1989-1994; Raban, 2008, 2009; Raban \& Holum, 1996; Vann, 1992). She is lying on a 3-meter-deep sandy bottom. She was discovered, surveyed and partly excavated in the 1980s (Fitzgerald 1994; Fitzgerald \& Raban, 1989). Even though the site is shallow, it is not an easy place to conduct an excavation. The numerous architectural debris on the shore do not make the site quite accessible. Moreover, the work, often interrupted, slowed down and delayed by storms bringing sediments, described by the first excavator as a "sisyphean effort". During some periods - which are impossible to anticipate - the site is covered by a thick layer of sand. Therefore, the first operations, conducted when the site was deeply covered, could bring only a glimpse of the shipwreck. The information collected during these operations is schematic or limited to a few parts of the shipwreck only. In spite of the lack of available data, M. Fitzgerald dedicated his $\mathrm{PhD}$ dissertation to this shipwreck (Fitzgerald, 1995). In the next decades, the scholars did not show any interest in the shipwreck, that suffered much from her exposed situation.

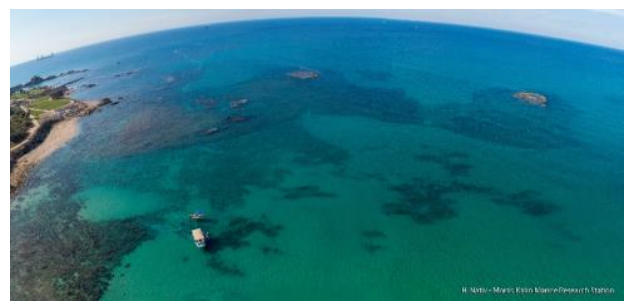

Figure 1: Aerial view of the excavation. Note in the foreground the support boat for the excavation and in the back on the left the Herodian harbour (photo: H. Nativ/Morris Kahn Marine Research Station).

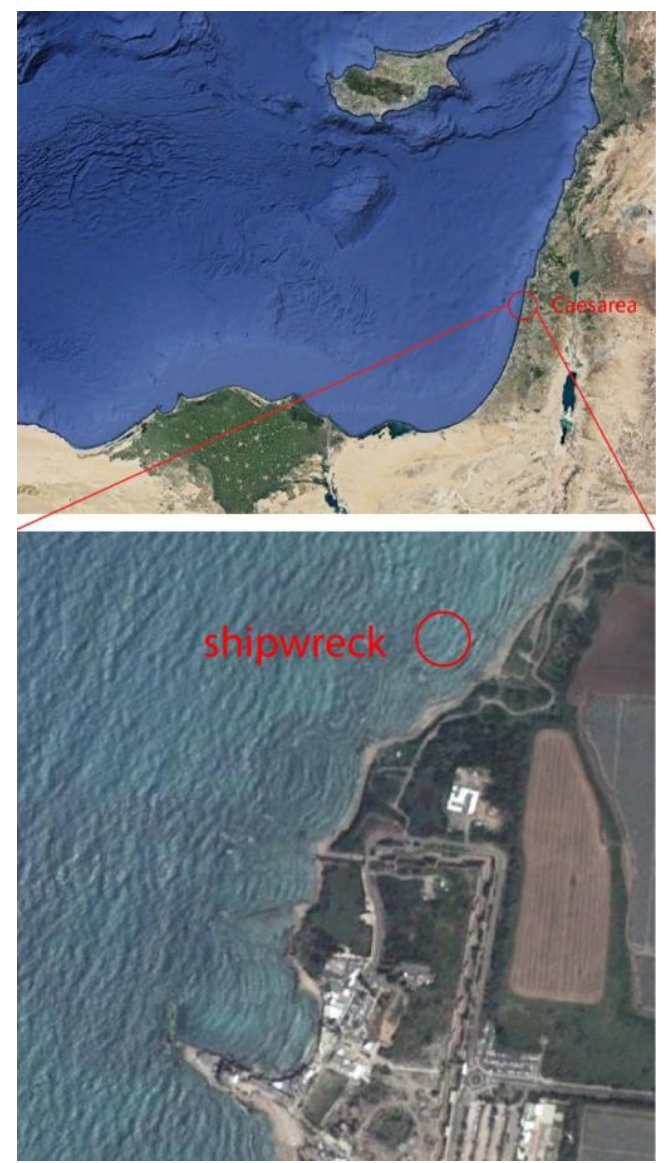

Figure 2: Location of the shipwreck. Top: the geolocation. Bottom: an aerial view of the excavation north to the Herodian harbour. 
The shipwreck was visited again in January 2017 by Jacob Sharbit (IAA). A new excavation was conducted in December 2017 (fig. 3) in order to fully document the shipwreck. In spite of the rough sea conditions, the sand lying on the central part of the wreck was removed and many pictures could be taken in order to provide a photogrammetric model. A second excavation season, carried out in November 2018 with a smaller team, was greatly facilitated by the good sea conditions and the fact that the wreck was only partly covered. It gave the opportunity to document the southern and northern parts of the wreck.

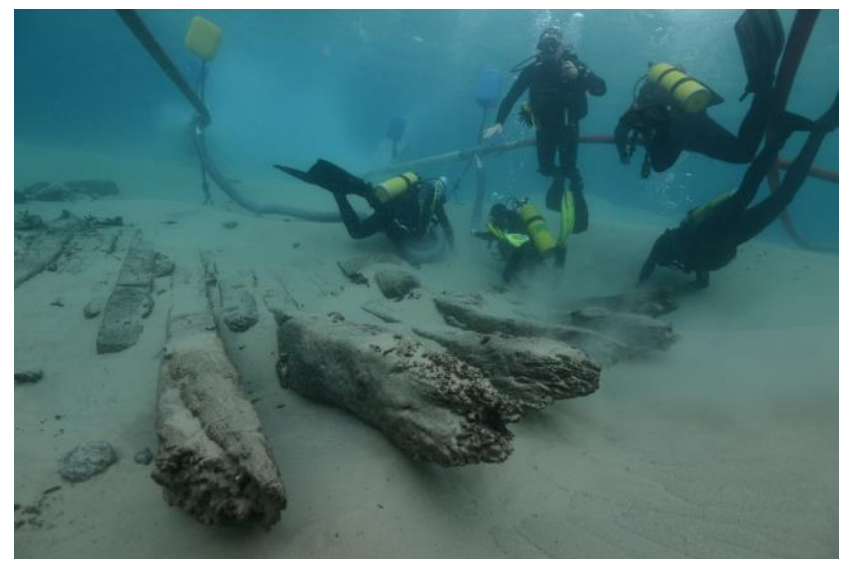

Figure 3: The shipwreck being excavated in December 2017 (photo: Nicolas Ponzone/Caesarea Shipwreck Project).

The shipwreck is assumed to be dated to the $1^{\text {st }}$ century CE, which makes her one of the very few early Imperial hulls excavated so far in the Eastern Mediterranean. The large size of her components shows that she was certainly part of a large ship. This is all the more interesting since the big tonnages are usually not much evidenced (Nantet, 2016). Therefore, the excavation aimed at focusing on the specific architectural features that might document the large Roman ships in the Eastern waters of the Mediterranean.

In that respect, the use of photogrammetry helps to develop an accurate documentation of the hull by providing a scientifically valid modelling of the shipwreck, while also being time-saving. Furthermore, it complements other interpretative techniques (e.g. drawings in situ) and offers a useful comparative framework. The photogrammetric model essentially allows to deepen the technical study during the post-excavation phase by: verifying the measurements, producing new ones, producing sections or images of certain details according to what is needed, creating orthomaps, implementing the model on a georeferenced map, etc. In other words, it is a very valid scientific tool.

In this regard, the use of photogrammetry could even allow researchers to study the bottom of the shipwreck without excavating it, which would minimize the risks both for the shipwreck and the divers. Theoretically, it could indeed be possible to obtain sufficient materials to create a partial model of the bottom of the shipwreck by: 1) conducting a limited probe under the planking to create a passage for the camera without penetrating the wreck (non-intrusive method); 2) shooting a bottom view photo coverage of the hull. In addition, by aggregating and merging the top and bottom model of the hull, it could even be possible to create a model through which we could see and analyse the constitutive elements of the wreck, including the construction techniques. It would be a significant step forward for underwater excavations.

\section{METHODOLOGY}

The major role of photogrammetry does not only lie in its capacity to provide documentation on the sites and archaeological objects, but also in its capacity to analyse the collected data. It is a real scientific tool, able to create plans and cross-sections, measure and even compare results. To do so, the elements that constitute the photogrammetric model - from the shooting to the creation of the 3D model - must be accurate and comparable to other verified and verifiable data, such as the Total Station measurements. If this is the case, the 3D model and the orthophoto projections can be used as scientific documents.

\subsection{Measurements and Interpretation}

To create a photogrammetric model usable as a tool for scientific studies, certain conditions must thus be met. The achievement of those lies in the ability to compare field data to the data obtained through the use of photogrammetry. Consequently, since the campaign began in December 2017, the various components of the wreck, especially the frames and the planks, were identified by numbers to facilitate the study. The details of the hull, such as the treenails, the pegs and the nails, were then marked. These marks were affixed in order to make them easier to study and to be seen in the photogrammetric model.

To provide an accurate documentation of the hull, the pictures (for the photogrammetry) were systematically complemented by technical data, including many hand drawings, carried out on a 1:1 scale on mylar paper (fig. 1). These drawings provide another source of information, relying on the human eye and carried out in the field conditions. They reduce the mistakes and give the possibility to check in case of doubt. It also provides some details that cannot be easily introduced through photogrammetry alone. Indeed, as these drawings are made on the field, it is possible to touch the hull, which provides an additional sensory source of information, that cannot be given by photogrammetry. In other words, these drawings provide an interpretation. They help to locate the details of the architectural features of the hull, such as the pegs, the tenons and the metal bolts.

Once the reference points were added to the hull, and the shipwreck drawn and photographed, wood samples were collected. They were conducted as a last procedure, so that they cannot be noticed on the pictures. Therefore, the photogrammetry implied a close coordination of the whole process.

As the study of a hull requires accurate measurements, it was decided to record the precise location of ten points with a Total Station. This task could be performed as the site is lying in shallow waters, close to the shore. The total station was set up on the shore, nearly $100 \mathrm{~m}$ away from the shipwreck. The prism was fixed on a long pole, handled by two divers: the first one operating on the surface in order to look at the horizontal level; the second one at the bottom to connect the end of the pole to the points. The chosen points were then conveyed to a third diver standing right next to the second one. Though the waves may impact the accuracy of the points, this method improved the overall measurement accuracy. 


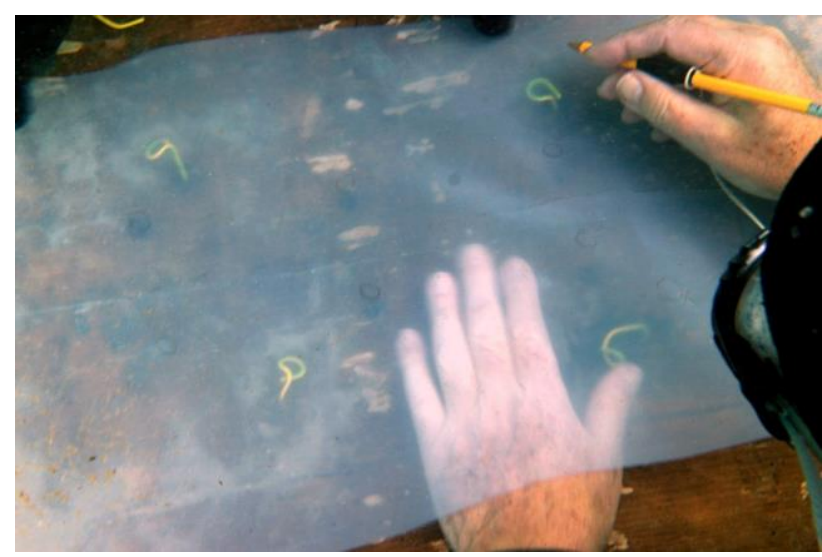

Figure 4: Caesarea shipwreck (excavation 2017): hand drawing of a planking joint with mylar paper. Note the green and yellow electric cords, that mark the location of the tenons (photo: Ariel Aba Eli/Caesarea Shipwreck Project).

\subsection{Imaging Production}

The imaging production for the 2018 campaign was conducted in two stages. The first one consists of an underwater shooting using a Canon PowerShot G12 camera, which offers a surprisingly low-margin of error of $0.524 \mathrm{~mm}$ (Capra, 2015), embedded in a waterproof case $W P-D C 52$. The operation aims at building an overlapping mosaic of images covering the desired sectors of the shipwreck. The pattern is done by forming strips and taking far shots as well as some fewer close shots, varying the angle to provide more details for the reconstruction stage. At each horizontal camera location, it is also important to cover the subject vertically (Lachambre, 2017). The whole process is achieved without the use of any artificial light.

The second stage consists of two major post-processing steps. First, a colour correction of every picture is made by correcting the white balance of the chromatic components " $\alpha$ " and " $\beta$ " (Bianco, 2015). This process is performed under a 32-bit format Adobe Lightroom. It is then converted into an 8-bit format to avoid any gamma difficulties during the photogrammetric reconstruction phase (the software uses a native 8-bit format). Secondly, an optic correction is performed. The whole process is achieved automatically in Adobe Lightroom following the camera and its specific lens (Canon 6.1-30.5 mm f/2.8-4.5).

\section{IMAGE-BASED MODELLING}

\subsection{The Software}

The whole photogrammetric model of the 2018 campaign is made using the RealityCapture software. The use of this software offers a substantial gain in time and significantly improves the quality of the document processing for the production of the photogrammetric models. Overall, "The efficiency and the quality of the reconstruction is far better than other software" (Lachambre, 2017). Unlike its competitors - such as Agisoft Photoscan or Autodesk ReCap, which requires a relatively long (or even very long) processing time - RealityCapture uses only extremely efficient algorithms that greatly reduce the processing time (from the alignment to the reconstruction of the 3D model). Furthermore, the adjustment of the measurements before and after the data processing allows us not only to correct the measurements, but also to make them more accurate.

\subsubsection{The Alignment}

After processing the images, they are imported into RealityCapture to begin the alignment phase. This whole process is done following some preferential settings depending on the size and the quality of the subject. For the shipwreck, the following settings were used: the maximum features per megapixel were set at $120.000 \mathrm{Mpx}$ and the maximum features per image chosen for the overlap were set at $90.000 \mathrm{Mpx}$. No image downscale factor was chosen. The whole alignment was made in 3 different components (north, middle and south parts of the shipwreck) which were merged into a single one. For the distortion correction, to compensate wrong results, the "Brown3 with tangential2" was used as it is best suited for cropped sensors.

\subsubsection{Setting Scales}

Despite a correct overlapping during the shooting, some images (13\%) were not aligned after the first alignment. This can be due, for instance, to a change in the light environment, or slightly blurred images. To improve the alignment, "control points" are added to different images representing the same position in the $3 \mathrm{D}$ space. With less than $2.3 \%$ of images not aligned, the next step can begin: the measurements. Though this stage can be done after the reconstruction phase of the model, it is useful to do it before in order to correct the potential distortions. Once the alignment is judged acceptable, it is time for the creation of the scales. To do so, test points are chosen in the images with the same points of reference (in our case a centimetric scale put on the scene).

\subsubsection{The Model}

After setting a reconstruction region of the desired surface, the model reconstruction is set by default into the "preview" mode. This mode produces a low polygon model that allows us to verify if the alignment and the scale were set correctly and to check whether the software handles the model properly. Once this process is considered correct, we can proceed to the "normal quality" version. Depending on the model, this quality can produce a relatively high polygon model (in our case 230 million). The reconstruction settings were adjusted with no downscale. The resulting model can be exported into an $8 \mathrm{Kx} 8 \mathrm{~K}$ high definition image. This, in turn, can be reconstructed into a "high quality" which produces about $3 \mathrm{x}$ the number of polygons but takes more than $14 x$ the time to calculate. Though the gain in quality seems important, the "normal quality" produces more than average results and is suited to what is needed in the context of this work.

\subsubsection{Texture}

In addition to a "colouring" option, Reality Capture also proposes a "texturing" option which offers more possibilities such as storing information on the colours by vertices across the mesh's surface. This process generates the colour textures from the source, i.e. the related photographs. This last method proved to be the most efficient one considering the good quality of the reconstructed dense cloud of our model. 


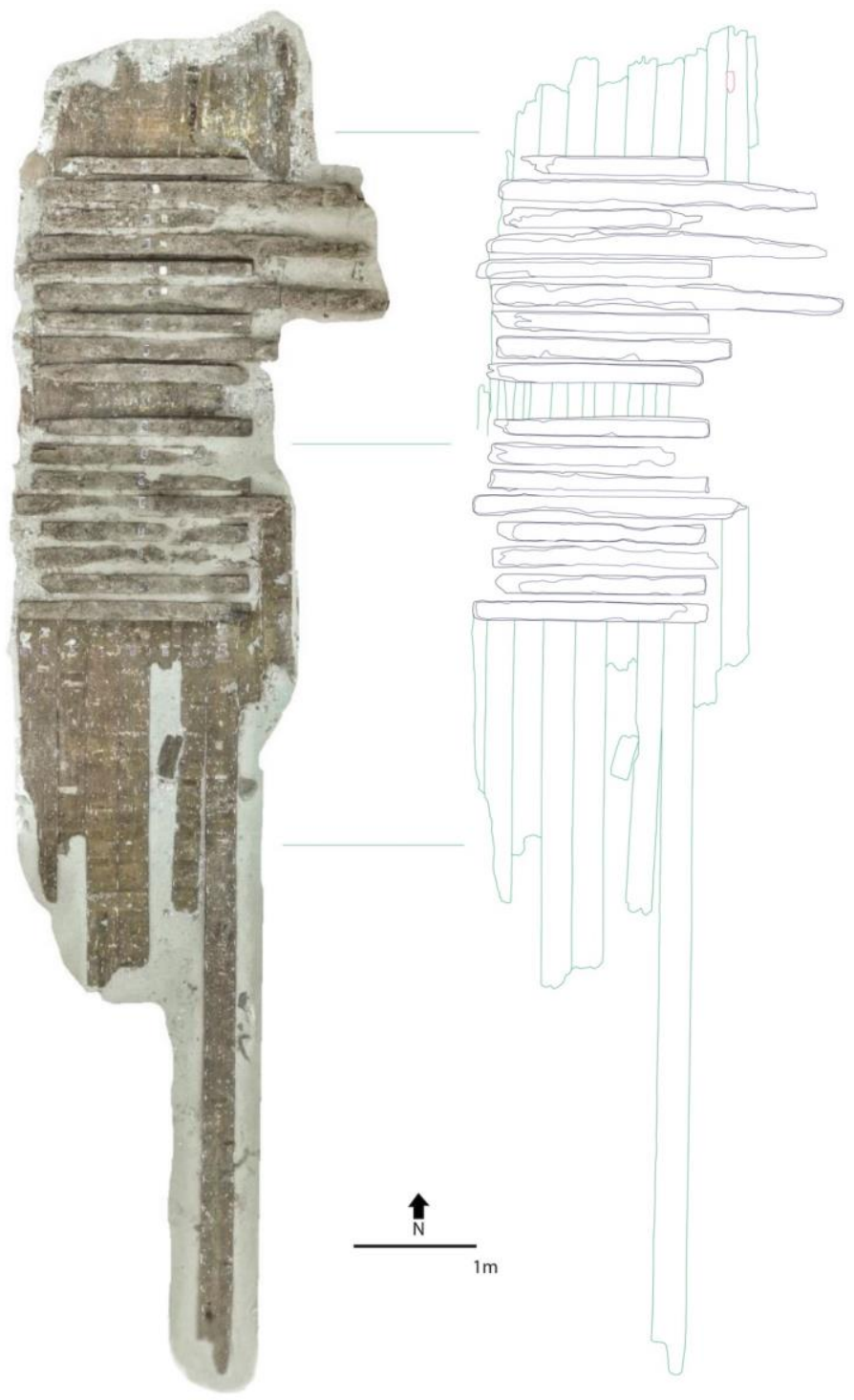

Figure 5. On the left, orthophoto of the shipwreck of the 2018 campaign from the photogrammetry model carried out with RealityCapture (photogrammetry: Bruno Derenne/Georges Verly). On the right, CAD orthomap produced from the orthophoto at scale (CAD: Verly Georges).

\subsubsection{Orthophotography}

The photogrammetric model also offers the possibility to create or export an orthophoto image based on the reconstructed model that can be used to produce a computer assisted drawing (CAD) to create an orthomap (fig. 5). This option is also at the heart of the archaeological imaging production. Indeed, this work is essential to obtain an overview of one or more sectors (fig. 6) and this without any deformation and/or distortion, all the while maintaining a 1:1 ratio (to the centimetre due to the accuracy of the reconstruction scale). The model also allows us to create sections of the desired sectors/artefacts in order to provide an overview of the shape for instance.

\section{RESULTS AND COMPARISONS}

Once the image-based model is finished and before proceeding to any cross-section or survey, it is essential to ensure that the model is true to scale. To obtain an assessment of the reliability and accuracy of the software, the whole scaling process is undertaken based on the reference points of the images. As already mentioned, the scaling can be done during the alignment of the model on the basis of reference points. Nonetheless, it can also be achieved once the model is finished, which allows us, in case of doubt, to adjust the scale (usually only for a difference of less than a centimetre). Though this can be carried out with RealityCapture, we have opted for "Autodesk ReCap", a software which can process heavy polygon-based models and rescale them. 


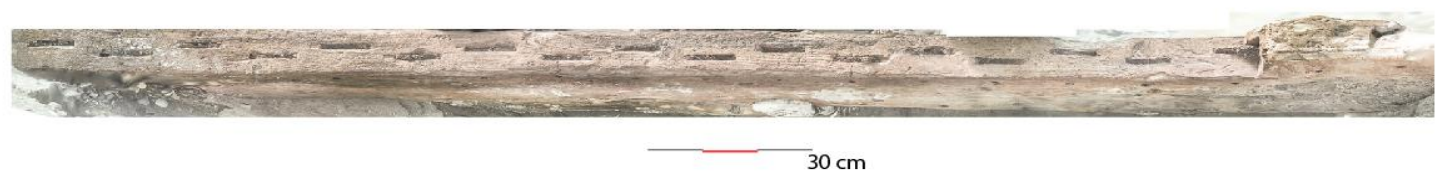

Figure 6. Orthophoto depicting the east-edge section of the plank 14. Note: this particular view allows us to show the mortises of the plank (photogrammetry: Bruno Derenne/Georges Verly).

\subsection{Comparisons between Technical Interpretation and Photogrammetric Measurements}

Knowing that the photogrammetric model is accurate, we can use the resulting data to discover additional information, such as: the size of mortises; the distance between them; the distance between treenails; the width of the frames and the planks. These data can also be used in other contexts, e.g. the compilation of statistics (with the average size of mortises for instance). It should be emphasized that the description of a hull requires very accurate measurements, as it implies a careful analysis of its fastening system.

On the other hand, the data extracted from the photogrammetric model can also be used as a benchmark between the measurements of the model and those taken in situ. In this regard, we noticed that the measurements calculated on the basis of defined control points during the excavation campaign of 2017 and 2018 showed some differences when compared to those resulting from the photogrammetric model based on the 2018 campaign. In other words, small discrepancies appeared when we compared elements for which we had precise measurements, e.g. the distances between tenons on the planking (table 1), between tenons on the frames of the shipwreck (table 2) and between mortises of the plank 14 on the east-edge section of the shipwreck (table 3). The reason for those discrepancies, ranging from $3 \%$ to $7 \%$ for the planking, from $1.9 \%$ to $27.8 \%$ for the frames and from $0 \%$ to $3 \%$ for the mortises, is that the technical data were taken in a difficult context of underwater archaeology.

It should be noted once more that these drawings were produced not for measurements but for an interpretative goal. Using the more precise data from the photogrammetric model, we were thus able to provide some measurements to the technical documents. The results being close to each other (with a difference of only a few centimetres), the technical data can be trusted and used not only for interpretation, but also for the measurements they can provide, as they have been rectified by the photogrammetric model.

\section{CONCLUSION}

The use of photogrammetry offers several benefits: namely an optimal use of resources, with techniques employed that are not only safer for the divers but also inexpensive, while also providing valid scientific results that can be accessed and used anywhere at any given moment without needing to be on site.

The comparisons between hand and photogrammetric measurements give the opportunity to estimate the efficiency and accuracy of photogrammetry. As a matter of fact, we were able to demonstrate that the measurements either taken on a flat surface or of very short distances were similar, regardless of the technique employed. For large structures (such as a shipwreck), photogrammetry is very useful because it ignores the difficult natural conditions (e.g. the swell, the sand, the current, the floating support, etc.) to which manual measurements are subjected. Thus, while the latter may include a margin of error, photogrammetry proves to be more accurate. This is crucial for the analysis of ancient hulls, especially when the climatic conditions can quickly change.

Nonetheless, the goal is not to replace the in situ interpretation of structures or artefacts with modelling. On the contrary, the photogrammetric models must be seen as complementary to other interpretative techniques to ensure the data accuracy, enrich the sources of information and save the excavation data on multiple supports. Our methodology is to multiply the means of archaeological data recording to enhance the data recording possibilities and the post-excavation studies.

The photogrammetric models are useful on a daily basis (according to the mission requirements), as a base to comment, describe, verify and compare measurements, make cross-sections (fig. 7) or even - in some cases - to annotate the stratigraphic units.

The process of understanding and interpreting the excavation site can be done on the basis of the models and processed within the day. Furthermore, as shown by the underwater excavation in Caesarea, this methodology can be carried out by small teams. It can be conducted in spite of rough sea conditions, that do not allow to work continuously more than a few days, as it is often interrupted by storms. All this contributes to improving the work of archaeologists, an interpretative work that combines technological knowledge with the sensory dimension inherent to each excavation (through sight and touch), three-dimensional modelling and the excavation method.

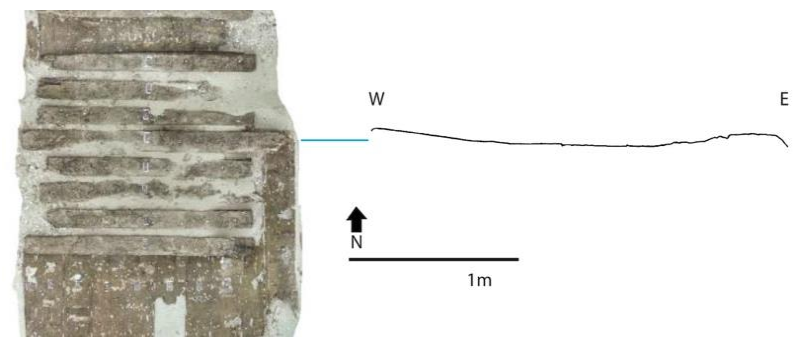

Figure 7. On the left, the blue stripe indicates the frame F22. On the right, an illustration of a section depicting the middle of the F22 frame created directly from the photogrammetric model (photogrammetry and CAD: Bruno Derenne/Georges Verly). 


\begin{tabular}{|c|c|c|c|c|c|c|}
\hline & \multicolumn{2}{|c|}{ IDM } & \multicolumn{2}{c|}{ PMM } & \multicolumn{2}{c|}{ Percentage difference between IDM and PMM } \\
\hline $\begin{array}{c}\text { Planking Joint } \\
\text { Number }\end{array}$ & $\begin{array}{c}\text { Length between } \\
\mathrm{T}(5) \text { and } \mathrm{T}(\mathbf{6})\end{array}$ & $\begin{array}{c}\text { Length between } \\
\mathrm{T}(\mathbf{1 1}) \text { and } \mathrm{T}(\mathbf{1 2})\end{array}$ & $\begin{array}{c}\text { Length between } \\
\mathrm{T}(\mathbf{5}) \text { and } \mathrm{T}(\mathbf{6})\end{array}$ & $\begin{array}{c}\text { Length between } \\
\mathrm{T}(\mathbf{1 1}) \text { and } \mathrm{T}(\mathbf{1 2})\end{array}$ & $\begin{array}{c}\text { \% difference between } \\
\mathrm{T}(\mathbf{5}) \text { and } \mathrm{T}(\mathbf{6})\end{array}$ & $\begin{array}{c}\text { \% difference between } \\
\mathrm{T}(\mathbf{1 1}) \text { and } \mathrm{T}(\mathbf{1 2})\end{array}$ \\
\hline $\mathrm{P} 7 / 8$ (South) & $13,1 \mathrm{~cm}$ & $14,4 \mathrm{~cm}$ & $13,5 \mathrm{~cm}$ & $13,5 \mathrm{~cm}$ & $-3,0 \%$ & $6,7 \%$ \\
\hline $\mathrm{P} 8 / 9$ (South) & $13,2 \mathrm{~cm}$ & $14 \mathrm{~cm}$ & $14,2 \mathrm{~cm}$ & $14,7 \mathrm{~cm}$ & $-7,0 \%$ & $-4,7 \%$ \\
\hline
\end{tabular}

Table 1. Measurements distances between different tenons on the planking joints P7/8 and P8/9. T stands for "tenon". In yellow, the interpretative drawn measurements (IDM). In blue, the photogrammetry model measurements (PMM). In green, the percentage difference between the ISIDM and the PMM. The total margin of error of the percentage difference between the IDM and the PMM for the length between the measurements of tenons 5 and 6 and tenons 11 and 12 is of $5.3 \%$.

\begin{tabular}{|c|c|c|c|c|c|c|}
\hline & \multicolumn{2}{|c|}{ IDM } & \multicolumn{2}{|c|}{ PMM } & \multicolumn{2}{|c|}{ Percentage difference between IDM and PMM } \\
\hline Frame number & $\begin{array}{l}\text { Length between } \\
T(5) \text { and } T(6)\end{array}$ & $\begin{array}{l}\text { Length between } \\
T(11) \text { and } T(12)\end{array}$ & $\begin{array}{l}\text { Length between } \\
T(5) \text { and } T(6)\end{array}$ & $\begin{array}{l}\text { Length between } \\
T(11) \text { and } T(12)\end{array}$ & $\begin{array}{l}\text { Length between } \\
T(5) \text { and } T(6)\end{array}$ & $\begin{array}{l}\text { Length between } \\
T(11) \text { and } T(12)\end{array}$ \\
\hline F10 & $8,9 \mathrm{~cm}$ & $9,6 \mathrm{~cm}$ & $11,5 \mathrm{~cm}$ & $9,6 \mathrm{~cm}$ & $-22,6 \%$ & $0,0 \%$ \\
\hline F11 & $22,6 \mathrm{~cm}$ & $x$ & $23,1 \mathrm{~cm}$ & $x$ & $-2,1 \%$ & $x$ \\
\hline F12 & $14,8 \mathrm{~cm}$ & $10,2 \mathrm{~cm}$ & $12,6 \mathrm{~cm}$ & $10,4 \mathrm{~cm}$ & $17,4 \%$ & $-1,9 \%$ \\
\hline F13 & $15 \mathrm{~cm}$ & $6,7 \mathrm{~cm}$ & $13,9 \mathrm{~cm}$ & $5,3 \mathrm{~cm}$ & $7,9 \%$ & $26,4 \%$ \\
\hline F14 & $21,5 \mathrm{~cm}$ & $12 \mathrm{~cm}$ & $18,8 \mathrm{~cm}$ & $12,7 \mathrm{~cm}$ & $14,3 \%$ & $-5,5 \%$ \\
\hline F15 & $7,7 \mathrm{~cm}$ & $\mathrm{X}$ & $9,9 \mathrm{~cm}$ & $\mathrm{X}$ & $-22,2 \%$ & $\mathrm{x}$ \\
\hline F16 & $5,7 \mathrm{~cm}$ & $6,7 \mathrm{~cm}$ & $5,6 \mathrm{~cm}$ & $5,8 \mathrm{~cm}$ & $1,7 \%$ & $15,5 \%$ \\
\hline F17 & $15,1 \mathrm{~cm}$ & $14,1 \mathrm{~cm}$ & $14 \mathrm{~cm}$ & $\mathrm{x}$ & $1,8 \%$ & $x$ \\
\hline F19 & $14,7 \mathrm{~cm}$ & $11,7 \mathrm{~cm}$ & $13,5 \mathrm{~cm}$ & $11,3 \mathrm{~cm}$ & $8,8 \%$ & $3,5 \%$ \\
\hline $\mathrm{F} 20$ & $14,6 \mathrm{~cm}$ & $11 \mathrm{~cm}$ & $13,1 \mathrm{~cm}$ & $9,6 \mathrm{~cm}$ & $11,4 \%$ & $14,5 \%$ \\
\hline F22 & $15,6 \mathrm{~cm}$ & $7,4 \mathrm{~cm}$ & $12,2 \mathrm{~cm}$ & $7,2 \mathrm{~cm}$ & $27,8 \%$ & $2,7 \%$ \\
\hline F23 & $16 \mathrm{~cm}$ & $9,1 \mathrm{~cm}$ & $14,3 \mathrm{~cm}$ & $8,5 \mathrm{~cm}$ & $11,8 \%$ & $7,0 \%$ \\
\hline F24 & $17,7 \mathrm{~cm}$ & $11 \mathrm{~cm}$ & $15 \mathrm{~cm}$ & $9,4 \mathrm{~cm}$ & $18,0 \%$ & $17,0 \%$ \\
\hline
\end{tabular}

Table 2. Measurements distances between different tenons of some frames of the shipwreck. "T" stands for "tenon". In yellow, the interpretative drawn measurements (IDM). In blue, the photogrammetry model measurements (PMM). In green, the percentage difference between the IDM and the PMM. The total margin of error of the percentage difference between the IDM and the PMM for the length between the measurements of tenons 5 and 6 is of $13.3 \%$ and for the length between the tenons 11 and 12 is of $9.4 \%$.

\begin{tabular}{|c|c|c|c|}
\hline Mortise Number & $\begin{array}{c}\text { Distance }(\mathbf{c m}) \text { between the } \\
\text { centres } \mathbf{M}(\mathbf{x}) \text { and } \mathbf{M}(\mathbf{x})\end{array}$ & $\begin{array}{c}\text { Distance } \mathbf{( c m )} \text { between the } \\
\text { centres } \mathbf{M}(\mathbf{x}) \text { and } \mathbf{M}(\mathbf{x})\end{array}$ & $\begin{array}{c}\text { Percentage difference of the } \\
\text { distance between the centres of } \\
\text { the mortises between DM and } \\
\text { PMM }\end{array}$ \\
\hline$M 2$ & $M 2-M 3: 14$ & $M 2-M 3: 14$ & $0 \%$ \\
\hline$M 3$ & $M 3-M 4: 13,8$ & $M 3-M 4: 13,8$ & $0 \%$ \\
\hline$M 4$ & $M 4-M 5: 13,3$ & $M 4-M 5: 13$ & $1,5 \%$ \\
\hline$M 5$ & $M 5-M 6: 13,3$ & $M 5-M 6: 12,9$ & $2,0 \%$ \\
\hline$M 6$ & $M 6-M 7: 14$ & $M 6-M 7: 13,7$ & $2,1 \%$ \\
\hline$M 7$ & $M 7-M 8: 12,8$ & $M 7-M 8: 13,1$ & $0,7 \%$ \\
\hline$M 8$ & $M 8-M 9: 14,2$ & $M 8-M 9: 14,1$ & $-1,5 \%$ \\
\hline$M 9$ & $M 9-M 10: 12,8$ & $M 9-M 10: 13$ & $0,0 \%$ \\
\hline$M 10$ & $M 10-M 11: 13,8$ & $M 10-M 11: 13,8$ & $2,3 \%$ \\
\hline$M 11$ & $M 11-M 12: 13,3$ & $M 11-M 12: 13$ & $-0,7 \%$ \\
\hline$M 12$ & $M 12-M 13: 13,8$ & $M 12-M 13: 13,9$ & $-1,5 \%$ \\
\hline$M 13$ & $M 13-M 14: 12,8$ & $M 13-M 14: 13$ & $-0,7 \%$ \\
\hline$M 14$ & $M 14-M 15: 14,3$ & $M 14-M 15: 14,2$ & $0,7 \%$ \\
\hline$M 15$ & $M 15-M 16: 12,9$ & $M 15-M 16: 13$ & $-1,4 \%$ \\
\hline$M 16$ & $M 16-M 17: 13,5$ & $M 16-M 17: 13,7$ & \\
\hline
\end{tabular}

Table 3. Measurements of the thickness, length and distances between different mortises on the plank 14. "M" stands for "mortise". In yellow, the interpretative drawn measurements (IDM). In blue, the photogrammetry model measurements (PMM). In green, the percentage difference between the IDM and the PMM. The total margin of error of the percentage difference between the IDM and the PMM for the distance between the centres of mortises is of $1.4 \%$. 


\section{ACKNOWLEDGMENT}

The excavation was conducted with the logistical support of the Leon Recanati Institute for Maritime Studies and the financial support of the University of Haifa. It was also subsided by the Honor Frost Foundation. We would also like to thank Ms. Florence Mirel and Ms. Charlotte Doyen for their careful reading of the text.

\section{REFERENCES}

Balletti C., Beltrame C., Costa E., Guerra F., Vernier P., 2015. Underwater Photogrammetry and 3D Reconstruction of Marble Cargos Shipwreck, ISPRS/CIPA workshop "Underwater 3D Recording and Modeling", Piano di Sorrento, Italy.

Capra A., Dubbini M., Bertacchini E., Castagnetti C., Mancini F., 2015. 3D Reconstruction of an Underwater Archaeological Site: Comparison Between Low Cost Cameras, ISPRS/CIPA workshop "Underwater 3D Recording and Modeling", Piano di Sorrento, Italy.

D’Amelio S., Maggio V., Villa B., 2015. 3D Modeling for Underwater Archaeological Documentation: Metric Verifications, ISPRS/CIPA workshop "Underwater 3D Recording and Modeling", Piano di Sorrento, Italy.

Demesticha S., Skarlatos D., Neophytou A., 2014. The $4^{\text {th }}$ century B.C. shipwreck at Mazotos, "Cyprus: new techniques and methodologies in the 3D mapping of shipwreck excavations", Journal of Field Archaeology. 39.2.

Drap, P., 2012. Underwater Photogrammetry for Archaeology, In Carneiro Da Silva, D. (ed), "Special applications of photogrammetry", https://www.intechopen.com/books/specialapplications-of-photogrammetry/underwater-photogrammetryfor-archaeology [Accessed: 11th February 2019].

Drap, P., Merad, D., Seinturier, J., Mahiddine A., Peloso D., Boi J.-M., Long L., Chemisky B., Garrabou J., 2013. Underwater programmetry for archaeology and marine biology: 40 years of experience in Marseille, France, Digital Heritage International Congress (DigitalHeritage). Vol.1, no., doi: 10.1109/DigitalHeritage.2013.6743718.

Fitzgerald M.A., 1994. "Chapter VI: The Ship", in Oleson J.P. (ed.), The Harbours of Caesarea Maritima. Results of the Caesarea Ancient Harbour Excavation Project (1980-85), Oxford, Bar International Series n ${ }^{\circ}$ 994, vol. 2, 163-223.

Fitzgerald M.A., 1995. A Roman Wreck at Caesarea Maritima, Israel: A Comparative Study of Its Hull and Equipment, $\mathrm{PhD}$ Dissertation, Texas A \& M University.

Fitzgerald M.A., Raban A., 1989. "III.S. Area Y: Roman Shipwreck", in Raban A. et alii, The Harbours of Caesarea Maritima: results of the Caesarea Ancient Excavation Project, 1980-1985, Oxford, B.A.R., 1989, vol. 2, 184-190.

G. Bianco, M. Muzzupappa, F. Bruno, R. Garcia, L. Neumann, 2015. A new color correction method for underwater imaging, ISPRS/CIPA workshop "Underwater 3D Recording and Modeling", Piano di Sorrento, Italy.
Lachambre S., Lagarde S., Jover C., 2017. Unity photogrammetry workflow https://unity3d.com/files/solutions/photogrammetry/UnityPhotogrammetry-Workflow_2017-07_v2.pdf [Accessed: 18th January 2019].

Nantet E., 2016. Le Tonnage des navires de commerce en Méditerranée du VIII ${ }^{\mathrm{e}}$ siècle av. l'è. chr. au VII ${ }^{\mathrm{e}}$ siècle de l'è. chr., Rennes, Presses Universitaires.

Oleson J.P. (ed.), 1989-1994. The Harbours of Caesarea Maritima: results of the Caesarea Ancient Excavation Project, 1980-1985, Oxford, BAR, 2. vol.

Raban A., 2009. The harbour of Sebastos (Caesarea Maritima) in its Roman Mediterranean context, Oxford, Archaeopress, coll. "BAR international series", $\mathrm{n}^{\circ} 1930$.

Raban A., Holum K.G. (eds.), 1996. Caesarea maritima: a retrospective after two millennia, Leiden, E.J. Brill, coll. "Documenta et monumenta Orientis antiqui", $\mathrm{n}^{\circ} 21$.

Raban A., 2008. Caesarea reports and studies: excavations 19952007 within the old city and the ancient harbor, Oxford, Archaeopress.

Vann R.L. (ed.), 1992. Caesarea papers: Straton's Tower, Herod's Harbour and Roman and Byzantine Caesarea, Ann Arbor (Mich.), Journal of Roman archaeology. 